\title{
Illa se iactet in aula! ${ }^{1}$
}

\author{
Illa se iactet in aula!
}

\author{
María Julia Bertomeu \\ Universidad Nacional de La Plata. Argentina / CONICET
}

Resumen. No pocos contemporáneos de Kant, incluidos algunos de sus discípulos, fueron pródigos en la crítica mordaz del carácter sistemático de su filosofía, y señaladamente, de la prosa filosófica en que ese carácter se expresaba. Otros, en cambio, no se privaron de manifestar el deseo de ver al filósofo aislado o acorralado en el recinto puramente especulativo del aula académica, en la buena - o en la mala- compañía de todos los políticos metafísicos de la época: "illa se iactet in aula!» Pero, temerosos de que los muros o los barrotes metafóricos del aula no bastaran a contener la propagación «popular» de las ideas del filósofo, completaron, con Burke, el verso de Virgilio en inequívoca alusión a barrotes seguramente menos simbólicos: "Illa se iactet in aula Aeolus, et clauso ventorum carcere regnet». Kant respondió en su momento a los unos y a los otros, por separado, y también de consuno, pero siempre desde la convicción, tenazmente mantenida, de la importancia de la teoría filosófica y de una disciplina metodológica, las cuales, aun si «impopulares» al comienzo, consideraba esenciales para una práctica moral y política tan hostil al paternalismo moral como a su contracara, el despotismo político (paternalista).

Palabras clave: Kant, paternalismo moral, despotismo político
Abstract. More than a few of Kant's contemporaries, including some of his disciples, were sharply critical of the systematic character of his philosophy, and, markedly, of the philosophical prose in which this character was expressed. Others, on the contrary, found solace in the prospect of seeing the philosopher either isolated or trapped in the purely speculative realm of the academic room, in the good - or bad-company of all the metaphysical politicians of the time: «illa se iactet in aula!» However, fearful that the walls or the metaphorical bars of the room were not enough to contain the «popular» propagation of Kant's ideas, they completed - in line with BurkeVirgilio's poem, distinctly alluding to surely less symbolic bars: "Illa se iactet in aula Aeolus, et clauso ventorum carcere regnet». Kant replied in time, writing both to each group separately and to everyone at once. But he did it always from his fiercely held conviction about the importance of both a philosophical theory and a methodological discipline, which, even when «unpopular» in the beginning, he considered essential elements of a moral and political practice that was so hostile toward moral paternalism as it was to its counterpart, a (paternalistic) political despotism.

Key words: Kant, moral paternalism, political despotism.

1 Este trabajo fue subsidiado por el Proyecto de Investigación de la Agencia Nacional de Investigaciones Científicas de Argentina, Raíces 2006 PICT 1795, y por el Proyecto del Ministerio de Investigación y Ciencia de España FF12009-10941. Agradezco los comentarios realizados a una primera versión de este trabajo por Antoni Domènech, Héctor Arrese Igor, María Victoria Costa y David Cassasas. 
No pocos contemporáneos de Kant, incluidos algunos de sus discípulos, fueron pródigos en la crítica mordaz del carácter sistemático de su filosofía, y señaladamente, de la prosa filosófica en que ese carácter se expresaba. Varios de ellos le aconsejaron que rescribiera completamente sus obras, aun, y mejor, que encargara la tarea a un traductor, a fin de ganar la popularidad necesaria para que su pensamiento captara la audiencia de un público no filosófico pero educado. ${ }^{2}$

Otros, en cambio, más pugnaces que mordaces, no se privaron de manifestar el deseo de ver al filósofo aislado o acorralado en el recinto puramente especulativo del aula académica, en la buena —o en la mala - compañía de todos los políticos metafísicos de la época:

«illa se iactet in aula!»

Pero, temerosos sin duda de que los muros o los barrotes metafóricos del aula no bastaran a contener la propagación «popular» de las ideas del filósofo, completaron, con Burke, el verso de Virgilio en inequívoca alusión a barrotes seguramente menos simbólicos: en su aula se jacte Eolo, pero sobre sus vientos imperen los muros de la cárcel:

"Illa se iactet in aula Aeolus, et clauso ventorum carcere regnet». ${ }^{3}$

Kant respondió en su momento a los unos y a los otros - a mordaces y a pugnaces - - por separado, y también de consuno, pero siempre desde la convicción, tenazmente mantenida, de la importancia de la teoría filosófica y de una disciplina metodológica, las cuales, aun si «impopulares» al comienzo, consideraba esenciales para una práctica moral y política tan hostil al paternalismo moral como a su contracara, el despotismo político (paternalista). ${ }^{4}$

2 Sobre este punto, véase Brandt, Reinhard, «Feder and Kant», Kant Studien, 80, 1989, Van der Zande, J., «In the Imagine of Cicero: German Philosophy between Wolff and Kant», Journal of the History of Ideas, vol. 56, N 3, 1995, pp. 419-442 y Garve, C., «Einige Beobachtungen über die Kunst zu denken», Versuche über verschiedene Geganstände aus der Moral, der Literatur und dem gesellschaftlichen Leben, Brealau, 1792-1802, II, 245-230, en Gesammelte Werke, Kurt Wölfel (edit.), Heldesheim, 1985-87, I.

3 Virgilio, Eneida, I, 140, citado por Burke en Reflexions on the Revolution in France, Inglaterra, Penguin, Pelican Classics, 1979, p. 149. Si bien Burke cita esa frase luego de un discurso de Price, lo hace en relación con los políticos metafísicos en general y, como hemos de ver más adelante, Kant se sintió aludido y respondió a su tiempo reproduciendo parcialmente la frase, en un contexto similar al del texto de Burke. Sobre la importancia de esta máxima para interpretar las claves de la contracrítica kantiana, que no alude directamente a Burke, véase P. Wittichen, «Kant und Burke», Historische Zeitschrift, 93, 1904, pp. 253-255.

4 Sobre el despotismo político (la monarquía absoluta) entendido como gobierno paternalista y su marcada diferencia con un gobierno patriótico. Kant, I., Kants Werke, Akademie Textausgabe, VIII, «Über den Gemeinspruch: Das mag in der Theorie richtig sein, taugt aber nicht für die Praxis», Berlin, Walter de Gruyter, 1968, p. 290. Versión castellana: «En Torno al Tópico: Tal vez eso sea correcto en teoría pero no sirve para la práctica», en Kant, I., Teoría y Práctica. Traducción de Pérez López, Francisco y Rodríguez Aramayo, Roberto. Madrid, Tecnos, 1993. En adelante TuP. 


\section{Sobre la popularidad de la filosofía: eclécticos y sistemáticos}

Algunos de los Popularphilosophen, particularmente Garve y Feder - primero anónimos y luego confesos autores de una polémica reseña de la Crítica de la Razón Pura que indignó a Kant, porque malintencionadamente confundía su filosofía con el idealismo de Berkeley y lo hacía aparecer como poco menos que necio - trataron a Kant como a un exponente de la «filosofía en la torre de marfil», una escolástica renovada para los nuevos tiempos, totalmente apartada del sentido común. Y si algo tuvieron en común los filósofos populares, puesto que hay marcadas diferencias entre ellos, fue, a partir de la década de los 80 , este tipo de crítica a la filosofía kantiana, tanto en el ámbito teórico como en el práctico. ${ }^{5}$

Garve era partidario de una filosofía ecléctica y derivativa, que prestara cuidadosa atención a diferentes programas filosóficos - especialmente, a la filosofía inglesa y escocesa - como un modo de liberarse de sectas y dogmatismos. Esa filosofía ecléctica, según Garve, era lo opuesto a la filosofía que, por sistemática e innovadora, resulta inútil para la sociedad, además de «impopular», puesto que se expresa en un lenguaje críptico y especializado. Quizá no sea exagerado afirmar que el principal objetivo del programa intelectual

5 Sobre los Popularphilosophen como movimiento filosófico político con un programa propio y, al mismo tiempo, como una reorientación de la filosofía wolffiana, véase: Batscha Zwi, Despotismos von jeder Art reizt zur Widersetzlichket. Die Französische Revolution in der deutschen Popularphilosophie, Frankfurt, Suhrkamp Taschenbuch Wissenschaft 759, 1989; Lestition, Steven, «Kant and the End of the Enlightenment in Prussia», The Journal of Modern History, vol. 65, N 1, 1993, pp. 57-112; Knudsen, Jonathan, Justus Möser and the German Enlightmment, Press Syndicate of the University of Cambridge, Cambridge, 2002, Van der Zande, Johan, «In the Image of Cicero, op. cit., Van der Zade, Johan, «Popular Philosophy and the absolute monarchy», en Bloom, Hans, Laursen, J. C. and Simonutti, L. (edit.), Monarchisms in the age of enlightenment, Toronto, University of Toronto Press, 2007, pp. 194-217. Sobre la recepción de la filosofía crítica kantiana entre 1781-1783, y especialmente sobre la crítica a la metafísica kantiana por parte de los anglófilos, véase: Beiser, F., «Moral Faith and the highest good», en Guyer, P. (edit.), The Cambridge Companion to Kant and the modern Philosophy, Cambridge, Cambridge U.P. 2006, pp. 630-663. Luego de la publicación del comentario, Garve envió una extensa y cordial carta a Kant en la que reconocía ser autor parcial de la reseña, asumía su responsabilidad, pero confesaba que no podía reconocer como suya la redacción final del texto, al mismo tiempo que seguía quejándose por la impenetrabilidad del lenguaje kantiano y le sugería que expresara de un modo más popular el conjunto de su sistema, pues de este modo se haría evidente que la reforma emprendida, o su divergencia con las opiniones de otros, era menor de lo que aparentaba ser. La carta está fechada en julio de 1783. Zehbe, Jürgen (edit.), Briefe an Kant, Göttingen, Vandehoeck \& Ruprecht, 1791, pp. 51 y ss. En el extenso apéndice a los Prolegómenos, Kant había desafiado a los desconocidos comentadores a que revelaran su identidad, y se animaran a mostrar contradicciones entre los principios básicos de su filosofía crítica, expuestos con meridiana claridad. Kant, I., Prolegomena zu einer jeden künftigen Metaphysik, die als Wissenschaft wird auftreten können, Kants Werke, op. cit., Tomo IV, «Anhang», pp. 372-383. Versión castellana: Prolegómenos. A toda Metafísica futura que pueda presentarse como ciencia. Traducción, Prólogo y Notas de Mario Caimi, Buenos Aires, Editorial Charcas, 1984, Apéndice, p. 157. 
de los Popularphilosophen fue poner en práctica un nuevo horizonte cultural para el público alemán. Con un medio como la traducción, con un criterio selectivo un tanto aleatorio, de textos clásicos antiguos y de ensayos modernos de filosofía y ciencia social inglesas y escocesas, diríase que su meta era promover la Bildung — la instrucción—, más que la Aufklärung, que es su contracara política.

Los Popularphilosophen compartieron la convicción kantiana del primado de la filosofía práctica, pero entendida, no como una disciplina normativa, sino como una ciencia empírico-descriptiva, fundamentalmente antropológica, y con estrechos lazos con la retórica, con la historia y la economía, con la estética y la pedagogía. La desconfianza de Kant ante este modo de hacer filosofía que «mira con ojos de topo» los problemas que interesan a la humanidad, fue compartida por Hegel, quien tuvo una pésima opinión sobre esta manera dominante y ecléctica de hacer filosofía - que identificaba con la Ilustración alemana- y de la cual dejó dicho que se trata de lo opuesto de la filosofía. ${ }^{6}$

La ingente tarea de traductor de Garve, cumplida mayormente a demanda de Federico el Grande - quien, dicho sea de paso, apenas mascullaba la lengua de Lutero y de Goethe - con la idea de hacer del alemán una lengua filosófica a la altura del latín o aun del francés de la época, permitió divulgar entre el público letrado alemán el De Officiis de Cicerón (1783), el texto The Institutes of Moral Philosophy de Adam Ferguson, la monumental obra The Wealth of Nations de Adam Smith, algunos textos de Shaftesbury y la Etica y la Política aristotélicas. Eso, entre otras traducciones de mayor «actualidad», como la de Mallet du Pan, el político contrarrevolucionario francés enviado a la Alemania para lograr apoyos para la causa monárquica, y a quien Kant replicaría en una nota de Sobre la paz perpetua. ${ }^{7}$

Estos textos, y muchos otros, fueron las fuentes de las que eclécticamente se nutrió Garve para popularizar la filosofía, consciente, al igual que Feder, de que el eclecticismo podía conducir a un moderado escepticismo ${ }^{8}$, pero

${ }^{6}$ Hegel, G. W. F., «Einleitung über das Wesen der philosophischen Kritik überhaupt und ihr Verhältnis zum gegenwártigen Zustand der Philosophie insbesondere», en Werke in zwanzig Bänden, II, Frankfurt am Main, Suhrkamp Verlag, 1970, pp. 182. En sus Lecciones de Historia de la Filosofía, Hegel se refirió a los populares como «afrancesados», según quienes la utilidad es la esencia de las cosas. Hegels Werke, op. cit. Band 20, pp. 308-309.

7 Sobre Garve como traductor, especialmente como traductor de Adam Ferguson, véase: Oz Salzberg, Fania, Tanslating the Enlightment. Scottish Civic Discourse in Eighteenth Century Germany, Oxford, Oxford University Press, 2000. El estudio inicial de Garve, que precede la traducción de los Institutes de Adam Ferguson, ocupa un tercio del libro. Como introductor de ideas de la ilustración escocesa en Alemania, dice Oz Salsberg, Garve fue importante pero también hizo de filtro, al punto que luego de la traducción, Ferguson fue conocido en Alemania simplemente como «un valioso estoico británico», op. cit., p. 242.

8 El «eclecticismo» tiene una larga trayectoria en filosofía. Ya Diógenes de Laercio se refería a los eclécticos como una secta, en sentido impropio, pues no constituyen una comunidad 
creyéndolo, al propio tiempo, una forma de liberarse de sectas y escuelas, de aunar la filosofía con la vida, de construir una filosofía para el mundo. ${ }^{9}$

La consigna de los «popularizadores», y característicamente también de Garve, era presentar los problemas filosóficos de una manera atractiva y fácilmente comprensible, con el auxilio ineludible de la retórica, de las metáforas y de las alegorías. La metáfora favorita de Garve —utilizada antes por Sulzer - era la del «filósofo que sale a dar un paseo» y se fascina por todo lo que ve, tan distinto del filósofo «sistemático», un viajero que, empeñado en tomar el camino más corto hacia su destino, preso del atajo y más interesado en la dirección y el emplazamiento geográfico del recorrido que en lo que hay tras los muros que al pasar observa, nunca llegará a conocer realmente el lugar que visita. Más allá de las aulas, decía Garve, las cosas son diferentes; la filosofía no sistemática se detiene a observar todo el recorrido, sin tener previamente en mente ningún objetivo particular. ${ }^{10}$

Pero, como intento mostrar más adelante, esta invitación a abandonar aulas y escuelas por parte de Garve y Feder, no es incompatible - como subraya el propio Kant - con el temor de Burke y sus partidarios germanos, con ese recelo ante una filosofía teórica - la metafísica política - que, a fuerza de soplar, abatiera muros y descerrajara barrotes, barriendo a la sociedad toda con su peligrosa bocana de Eolo. La crítica definitiva de Kant, fechada en el año 1793, iba dirigida contra todos ellos: contra quienes le censuran mordazmente la «impopular» prosa y el rigor metodológico de una filosofía sistemá-

cuyas proposiciones estén en total concierto. Diógenes Laertius, Leben und Meinungen berühmter Philosophen, Hamburg, Felix Meiner Verlag, 1967, I, 16-20, p. 12. En la literatura especializada sobre el tema, existe cierto acuerdo en afirmar que no se trata ni de una escuela ni de una tradición, ni tan siquiera un método, y que en el período de la baja Ilustración tomó la forma de una «libertad de pensar» o filosofar, opuesta a las escuelas y sistemas. Como todos los conceptos filosóficos, el término eclecticismo también está históricamente indexado. Para una discusión contemporánea interesante sobre el tema del eclecticismo: «Zur Entwicklung und Eigenart der "eklektischen" Philosophie», Zeitschrift für historische Forschung, 18 (1991), Muslow, Martin, «Eclecticism or Skepticism? A Problem of the Early Enlightenment», Journal of the History of Ideas, 58, 3, 1997, pp. 465-477; Kelley, D., «Eclecticism and the History of Ideas", Journal of the History of Ideas, 62, 4, 2001, pp. 577-592.

9 Si la Popularphilosophie constituye un movimiento fílosófico unitario o simplemente contestatario, es algo que todavía no ha sido suficientemente probado. Tanto Van der Zande como Batscha intentan demostrar, a su manera, que se trata de un movimiento filosófico propio, y ambos coinciden en identificar a sus representantes alemanes del XVIII tardío con la defensa del estado absoluto, la única garantía de las reformas políticas y pedagógicas necesarias en ese momento. Según Van der Zande, citando un texto de J. G. Sulzer, se trata de una «combinación de filosofía práctica y talento literario, con la finalidad de educar a un público letrado para que se convierta en buen ciudadano de una monarquía absoluta». Van der Zande, J., «In the Image of Cicero», op. cit., p. 421.

10 Garve, C., Einige Beobachtungen über die Kunst zu denken: Versuche über verschiedene Gegenstände aus der Moral, Litteratur und dem Gesellschaftigen Leben (1772-1808). La referencia ha sido tomada del texto de Van der Zande, «The Image of Cicero...», op. cit., pp. 426-427. 
tica que le confina en la academia, y contra quienes, con indisimulable pugnacidad política, expresan, al revés, el vivo deseo de ver tras los barrotes cualquier intento sistemático de teorización normativa. Que, de paso, el protoutilitarista Hobbes se lleve unos cuantos golpes es cosa que tampoco carece aquí de interés.

La respuesta de Kant a Garve - con quien mantuvo un respetuoso intercambio epistolar-, y en general, a los Popularphilosophen, fue clara y contundente, en el «Prólogo» y el extenso "Apéndice» (en donde Kant solicita al autor de la reseña que salga del anonimato) de su texto Prolegómenos (1783); en el «Segundo Prólogo» a la Crítica de la Razón Pura, por supuesto, en la primera parte (el contra Garve) de su valiente y combativo texto de 1793: «A propósito del dicho: «Lo que puede valer en la teoría, de nada sirve en la práctica», y también en Sobre la Paz Perpetua de 1795. Como puede apreciarse por las fechas, la disputa fue un leitmotiv en la obra kantiana.

En el polémico «Prólogo» de los Prolegómenos, Kant comienza por reconocer que:

«No a todos les es dado escribir de un modo tan sutil y al mismo tiempo tan atrayente como a David Hume, ni tan profundamente y a la vez con tanta elegancia como a Moses Mendelssohn.» ${ }^{11}$

Concede de grado que, deliberadamente, ha preferido "sacrificar la elegancia de la prosa a poner estorbos en el estilo pedagógico de su monumental Crítica. Y pasa entonces a fijar una posición muy clara en la cuestión de la popularidad o impopularidad de la filosofía. Lo cierto es que el asunto -al revés de lo que pretenden algunos exégetas - nunca le resultó indiferente, y lo que hizo fue afianzar su punto de vista:

«.... yo habría podido dar a mis trabajos $-\mathrm{o}$ de eso, al menos, me jacto- - un carácter popular, si lo único que me hubiera interesado fuera esbozar un plan, dejando a otros su ejecución, y si no me tomara tan a pecho el bien de una ciencia a la que tanto tiempo he dedicado. Pues, ciertamente, se requería mucha tenacidad, y aun no poca negación de sí propio, para resistir a la tentación de una recepción temprana y favorable a la espera de un aplauso, aunque tardío, duradero.» ${ }^{12}$

Es claro que Kant no podía mostrarse dispuesto a aceptar la sugerencia de Feder y encomendar la tarea expositivo-popularizadora de su obra filosófica a un «traductor». No se olvide, además, que para Feder y Garve el traductor era un verdadero filósofo, porque traducir - hermenein - es «interpretar»; ni, por lo demás, que los Popularphilosophen estaban convencidos de que la

11 Kant, I., Prolegomena zu einer jeden künftigen Metaphysik, die als Wissenschaft wird auftreten können, «Vorwort», Kants Werke, op. cit., Tomo IV, p. 262 (salvo que se indique lo contrario, he introducido cambios a la versión castellana). Versión castellana, p. 19.

12 Kant, I., KW, IV, Prolegomena, op. cit., p. 262, versión castellana, op. cit., p. 19. 
coherencia de las ideas es más importante aún que lo que ha dicho verdaderamente el filósofo. ${ }^{13}$ La mayoría de las traducciones de Garve, especialmente la de De Officiis, iban precedidas de extensísimos comentarios por parte del traductor-filósofo, uno de cuyos principales cometidos era la comparación de obras y autores y de hechos pasados con hechos recientes, así como comunicar empatía con el escritor. ${ }^{14}$

Ahora bien, Kant no deseaba encomendar su obra a los intérpretes, y mucho menos ser interpretado por aquellos filósofos que:

«se quejan por falta de popularidad, de amenidad o de comodidad, justamente cuando se trata de la existencia de un conocimiento apreciado e indispensable para la humanidad, un conocimiento que no puede obtenerse sino obedeciendo a las reglas más estrictas de la precisión metodológica...» ${ }^{15}$

La ironía kantiana: «justamente los filósofos se quejan por falta de amenidad y comodidad», y su alusión a la precisión metodológica cuando se trata de un conocimiento indispensable para la humanidad, van precedidas por otra ironía sólo inteligible en el contexto de su discusión con algunos filósofos populares que, como el propio Garve, eran verdaderos entusiastas del programa y del estilo filosófico humeano.

Unas pocas líneas antes de su explícita alusión a los «popularizadores», Kant recuerda que su crítica de la razón no es otra cosa que «el problema de Hume en su máxima amplitud», y confiesa que, por eso mismo, temía que corriera la misma suerte que cuando «el problema» fue formulado por primera vez, a saber: que se lo malinterpretara. Sí, que se lo malinterpretara: porque se limitarían a hojear la obra, sin disposición a leerla, árida como es, reñida como está con los conceptos habituales y, encima, extensa. Ésta era, con toda probabilidad, una respuesta directa de Kant a Garve y a Feder, aunque sin mencionarlos: no entendían su obra, como quedaba claro en la reseña antes aludida, ipero tampoco se había entendido la complejidad del pensamiento humeano, aparentemente —a juzgar por su grácil y expedita prosa-, tan llano!

Es fácil darse hoy cuenta de la razón que llevaba Kant en este punto: ni el depurado y ameno estilo literario hizo de Hume un ecléctico, ni el prestar cum-

13 Y de incoherente tachó Garve a Kant en su posición sobre la Revolución Francesa, porque defendía en la práctica (de la Revolución) lo que condenaba en la teoría. El mismo Garve que, ya maduro, se espantaba por el carácter violento de la revolución en las ideas en Alemania, en alusión directa a quienes, como Kant, defendían la Revolución Francesa incluso después de Thermidor. Garve, C., «Drei Texte über Theorie und Praxis», en Heinrich, D., Kant, Gentz, Rehberg, Über Theorie und Praxis, «Anhang» Frankfurt, Suhrkamp Verlag, 1967, pp. 135-150.

14 Es muy posible que Kant leyera a Cicerón en la traducción de Garve, y es evidente que conocía muy bien el extenso estudio introductorio, a juzgar por su cita en el texto TuP (Contra Garve), op. cit., $K W$, VIII, p. 286, nota, versión castellana, op. cit., p. 19, nota.

15 Kant, I., KW, IV, Prolegomena, op. cit., p. 261; versión castellana, op. cit., p. 17. 
plida atención a la indexación histórica de los conceptos filosófico-políticos le llevó, como a los popularizadores, a eludir su contrastación con una teoría filosófica robusta. ${ }^{16}$ Por otro lado, ¿cómo era posible que Hume se utilizara como un arma en contra del «dogmatismo» de su crítica de la razón, siendo así que justamente Kant creía que Hume «lo había despertado del sueño dogmático»? Posiblemente la razón fuera que los textos humeanos favoritos de Garve no eran los «abstractos y filosóficos», como el Tratado de la naturaleza humana, sino los trabajos sobre historia de Inglaterra y sobre la religión natural.

Bien sabido es que, en su «Segundo Prólogo» a la Crítica de la Razón Pura (1787), Kant se lanza abiertamente tanto contra los dogmáticos de las escuelas como contra los filósofos popularizadores, y lo hace sirviéndose de léxico clara y expresamente político. En lo referente al dogmatismo de las escuelas, y para escándalo de las mismas, resultan iluminadoras sus reflexiones sobre la utilidad para el pueblo de una crítica de la razón especulativa que corte de raíz las pretensiones de «cogniciones exuberantes» de las escuelas arrogantes. Decía Kant:

«de ahora en adelante, las escuelas deben aprender a no adjudicarse a sí mismas, en un punto que concierne al interés humano universal, una inteligencia superior y más amplia que aquella que la multitud (digna para nosotros del mayor respeto) puede alcanzar también con la misma facilidad... La mudanza toca entonces meramente a las pretensiones arrogantes de las escuelas, que en esto (como, por otra parte, con justicia, en muchos otros asuntos) quisieran ser tenidas por las únicas conocedoras y depositarias de tales verdades, de las que sólo el uso comunican al público, conservando para sí la clave... (quod mecum nescit, solus vult scire videri: aquello que no sabe cuando está conmigo, pretende saberlo cuando está solo)... Si los gobiernos hallan conveniente ocuparse de los asuntos de los literatos, sería mucho más adecuado a su sabio cuidado de las ciencias y de los hombres el favorecer la libertad de este tipo de crítica — sólo a través de la cual las elaboraciones de la razón pueden ser llevadas a un suelo firme - que patrocinar el ridículo despotismo de sus escuelas, que levantan una ruidosa alarma de peligro público en cuanto alguien se avilanta a rasgar sus telarañas, de las que el público, empero, jamás tuvo noticia, y cuya pérdida, por tanto, tampoco puede nunca sentir...» ${ }^{17}$

${ }^{16}$ A diferencia de Hume y de gran parte de sus supuestos mentores - un arco tan amplio que va de Wolff y Leibniz a Hume, Locke, Ferguson e incluso a Thomasius - los eclécticos y populares de finales del XVIII alemán intencionadamente decidieron no adherir a teoría alguna, pues eran «eclécticos asumidos» que seleccionaron textos y autores según su popularidad, sentido común y aplicabilidad. Y estos criterios son los que hacen valer frente a los filósofos sistemáticos y metafísicos, que desprecian el sentido común o se expresan en lenguajes carentes de popularidad, como el filósofo de Königsberg. Sobre los filósofos populares del XVIII tardío alemán y la influencia de la filosofia escocesa: Kühn, Manfred, Scottisch Common Sense in Germany 1768-1800. A Contribution to the History of Critical Philosophy, McGill-Queen's University Press, 1987.

17 Kant, I., «Kritik der reinen Vernunft», KW, op. cit., IV, Segundo Prólogo (1797). Versión castellana: Crítica de la Razón Pura, traducción, introducción y notas de Mario Caimi, 
Ciencia abierta y crítica es lo que Kant aconseja a los gobiernos ante el despotismo de unas escuelas que tocan a rebato y a alerta y ven en la filosofía un peligro público, en cuanto empiezan a rasgarse las confundentes telarañas que, al tiempo que les sirven a ellas de parapeto, sirven también, precisamente, para estorbar el acceso del pueblo, no sólo al uso, sino a las claves que la razón crítica aporta para conocer todo aquello que concierne al interés humano universal. Así pues, no sólo los gobiernos y sus funcionarios, sino también las escuelas se atraviesan en el camino por el que el pueblo llano, digno del «mayor respeto» de Kant, puede cumplidamente atreverse a saber: sapere aude!

Nuestro filósofo no ha podido ser más claro en este extremo: el papel de la filosofía y del filósofo - aun a riesgo de ser considerado un «peligro público»- consiste en comunicar al pueblo las claves necesarias para averiguar, sin tutelas, todo aquello que concierne al interés de la humanidad.

El Prólogo termina con una concesión que es, al propio tiempo, un grave reproche a los filósofos populares: Kant deja para los hombres de talento literario, capaces de maridar felizmente las profundidades abisales de su inteligencia con la gracilidad y el donaire expositivos, la tarea de perfeccionar la obra de quien, como él mismo, se sabe escritor de prosa limitada; pero sólo a condición de que la entiendan cabalmente como teoría compleja y consistente que es. Entonces, y sólo entonces, los hombres imparciales, inteligentes y verdaderamente populares podrán continuar su labor y limar cantos, pulir asperezas y allanar caminos. Kant no estaba dispuesto a ser popular y prosísticamente elegante a costa de privar de consistencia, solidez y disciplina metodológica a su teoría, virtudes cognitivas, todas ellas, que le parecían de todo punto inexcusables, y no sólo por razones teórico-sistemáticas y metodológicas, que también, sino por su voluntad política expresa de comunicar al pueblo llano las claves de las verdades que las escuelas se reservan arbitrariamente para sí y los filósofos no-sistemáticos reinterpretan no menos arbitrariamente a su manera.

Buenos Aires, Colihue, Colección Clásica, 2007, p. 32. En este mismo sentido - y mediante el uso de metáforas claramente políticas - se expresaba Kant en el \& sobre «La disciplina de la razón pura con respecto a su uso polémico» de su primera Crítica: «la razón pura debe someterse a la crítica en todas sus empresas.... carece de autoridad dictatorial... su sentencia nunca es sino el consenso de ciudadanos libres, cada uno de los cuales tiene que poder expresar sin temor sus objeciones e incluso su veto». $K W$, A739-B765, versión castellana, op. cit., pp. 765-766. En la nota citada en el texto, Kant también se refiere al dogmatismo de las academias tradicionales, que tienen el monopolio corporativo del saber y están patrocinadas por los gobiernos. En su texto posterior Streit der Fakultäten (1798) Kant dejaría bien claro el contraste entre la ciencia abierta y crítica y la ciencia patrocinada por los gobiernos para la «felicidad» del pueblo. 


\section{Los «honorables caballeros», el hiperrealismo y la teorización sistemática}

Ahora bien; entre 1786 y 1798, el clima filosófico-político alemán cambia, y por supuesto, cambia radicalmente en Francia. Es el período final de la Ilustración, la época en que se pone de moda la crítica a sus pretendidos excesos, la época del Edicto de Wöllner censurando el escrito de Kant sobre la Religión, la época que abarca los inicios y la progresiva radicalización de la Revolución Francesa, la época en que Kant forcejea filosóficamente con la demostración del poder de la razón para disputar los supuestos «hechos» que, fundados en la tradición y en una pretendida naturaleza real de los hombres, articulan el discurso filosófico de la Contrarrevolución europea. Particularmente agudo se mostrará Kant en la crítica del ideologema conservador que, apelando a un supuesto realismo o a un pesimismo antropológico, pretende encerrar toda teorización normativa tras la infranqueable puerta de siete llaves de «los hombres tal y como éstos realmente son»:

«Dicen que hay que tomar a los hombres tal como son, y no como los ignorantes presuntuosos o los soñadores bien intencionados fabulan que deberían ser. Pero, en lugar de tal cómo son, deberían decir: tal como los hemos hecho por medio de una injusta coacción de pérfidas maquinaciones sugeridas al gobierno: es decir, obstinados y prontos a la rebelión; con lo que, como es natural, en cuanto se aflojan un poco las bridas que los mantienen sujetos, se siguen tristes consecuencias que reafirman las profecías de aquellos estadistas que se dicen sagaces...» ${ }^{18}$

Ya se ve aquí que lo que con superlativa displicencia de buen conservador llamó Ortega muchos años después el «ademán normativo» de Kant ${ }^{19}$ no es la crítica irrealista de un iluminado hostil a todo realismo político, sino la muy realista crítica que el pensamiento normativo está obligado a hacer de la peor ilusión en política práctica: la soberbia fantasía hiperrealista que cree de todo punto prescindible la disciplina crítica normativa en la acción política; quien cae en esa peligrosa fantasía pseudorrealista, más que a un verdadero hombre de acción, asemeja a los profetas y eclesiásticos que forjan y consuman las agoreras profecías que anuncian. El texto está dirigido a políticos y eclesiásticos, aunque las objeciones a una posición como la de Garve y la de los prácticos en general - tanto en la moral como en la política- que pretenden que una práctica calculada en orden a un resultado probable con arreglo a una experiencia acumulada hasta la fecha domine la teoría, están en perfecta

18 Kant, Inmanuel, Der Streit der Fakultäten, AA, VII, op. cit., p. 98.

19 Cfr. A. Domènech, «Ortega y el "niño mimado de la historia". O qué se puede aprender políticamente del uso incongruo de una metáfora conceptual», en R. R. Aramayo y F. Álvarez (Comps.): Disenso e incertidumbre. Un homenaje a Javier Muguerza, Plaza y Valdés, Madrid/México, 2006, p. 358. 
sintonía con la cita anterior, expresada, esta vez, mediante un lenguaje llano y francamente combativo.

No es posible aquí estudiar con el detalle que merecerían todos y cada uno de los interesantes textos de este período; me concentraré, entonces, en el trabajo de Kant sobre TuP (1793) y en algunos pasajes de Sobre la Paz Perpetua (1795). Ambos textos, y especialmente el opúsculo sobre «Teoría y Práctica», según pretendo mostrar, aportan la clave para afianzar la hipótesis inicial: Kant consideró pertinente matar a varios pájaros de un solo disparo, esto es, realizar una misma y definitiva crítica tanto de dos exponentes de la Popularphilosophie - Garve y Mendelssohn-, como del contrarrevolucionario Burke y a sus seguidores alemanes, F. Gentz y A. W. Rehberg, aprovechando, significativamente, la ocasión para ajustar cuentas también con Hobbes, el más importante teórico de la Contrarrevolución inglesa en el siglo anterior. ${ }^{20}$ La inmediata respuesta de Gentz y Rehberg en el Berlinische Montaschrift ${ }^{21}$ es prueba contundente de que se sintieron directamente atacados. Pero, ¿por qué eligió Kant también a Garve y Mendelssohn como blanco de una crítica que, aparentemente, iba dirigida a Burke y sus seguidores alemanes?

Al presentar el esquema de su trabajo, Kant comienza por recordar que todo está perdido cuando la práctica no va acompañada por una teoría crítica (el canon de la razón en la práctica), esto es, cuando la práctica orientada según el resultado probable de la experiencia pasada domina a la teoría. Kant continúa el texto con un argumento en el que sugiere, sin dar nombres, contra quién, o contra quiénes, va dirigida su crítica, y por qué:

«La división a que procedo en el presente tratado es conforme a los tres distintos puntos de vista, a partir de los cuales aborda el problema el honorable caballero que rechaza con insolente displicencia cualquier teorización sistemática. Esto es, a la triple cualidad de: 1) hombre privado, pero, con todo, hombre de negocios; 2) hombre miembro de un Estado; 3) hombre de mundo (o, en general, ciudadano del mundo). El caso es que esas tres personas distintas coinciden en una cosa, que es en arremeter contra el

20 Ambos pensadores germanos, al igual que Burke, fueron detractores de la política fundada en la razón, y no en los hechos; y de una teoría del estado construida como una ciencia $a$ priori.

${ }^{21}$ La respuesta de Gentz fue en diciembre de 1793: «Nachtrag zu der Räsonmente des Herrn Professor Kant ubre das Verhältnis zwischen Theorie und Praxis», y la de Reberg en febrero de 1794: «Über das Verhältniss der Theorie zur Praxis», editados por Heinrich, D., Kant, Rehberg, Gentz. Über Theorie und Praxis, Francfort, 1967. Hay una excelente versión castellana (parcial) de la crítica de Gentz, precedida de un profundo y bien informado comentario crítico: Hernández Marcos, Maximiliano: Friedrich von Gentz, «Observaciones complementarias al razonamiento del Sr. Profesor Kant sobre la relación entre teoría y praxis», con presentación preliminar del texto titulada: «Gentz, divergencia e insuficiencia del criticismo político de Kant» (pp. 227-247), Murcia, Res Pública, vol. VI, 2000. Sobre la crítica de Gentz a Kant y la respuesta kantiana, véase: Bertomeu, María Julia, «Contra la Teoría (de la Revolución Francesa)», en prensa en Res Pública, Murcia. 
académico que teoriza normativamente sobre lo mejor para todas ellas, tomadas de consuno: puesto que esas personas se jactan de entender mejor el asunto, pretenden confinarle en su aula de académico (illa se iactet in aula!), como si de un pedante se tratara que, incapaz para la práctica, sólo sirviera para atravesarse en el camino de la experimentada sabiduría de ellas.» 22

Pistas para interpretar el texto y su parcial cita de Virgilio - incluida, completa, por Burke en su escrito contrarrevolucionario- las hay, y aun de sobra.

En primer lugar, su irónica referencia a los «honorables caballeros» (Ehrmänner), epíteto del que Burke, tan seriamente, hace uso y abuso en su texto (gentlemen). En segundo lugar, la clara alusión de Kant a la pretensión de confinar a los académicos que teorizan normativamente tras los barrotes del aula. Vale la pena recordar el patetismo con que Burke declaró su protréptica admonición:

«... no les dejemos romper los barrotes de su cárcel, no les dejemos soplar como una levantada y asolar la tierra como un huracán, no les dejemos destruir los manantiales profundos y arrastrarnos a todos en el naufragio». ${ }^{23}$

Por otra parte, en su discusión con Hobbes sobre la relación entre teoría y práctica en la política ${ }^{24}$, Kant optó por volver a analizar normativamente la famosa tríada revolucionaria: libertad, igualdad y fraternidad (convertida por Kant en Selbständigkeit). Esa tríada, vale la pena recordarlo, constituye el hilo conductor de la refutación burkeana del programa intelectual de la Revolución francesa, y también de Gentz y Rehberg.

Por último, aunque no último en importancia a los fines de este trabajo, la crítica de Kant va dirigida a los que abominan de la teoría sistemática, en clara alusión a quienes, como Garve, optaron por un eclecticismo filosófico miope y acríticamente atado a la historia, a las tradiciones y a las trayectorias de los gobiernos despóticos, un eclecticismo que, por decantación, terminó desembocando en una cerrada defensa de la monarquía absoluta y de la socie-

22 Kant, I., TuP, KW, VIII, op. cit., pp. 277, versión castellana, p. 7.

23 Burke, Reflections, op. cit., p. 149.

24 No me ocuparé de la crítica de Kant a Hobbes en este trabajo, no porque no tenga interés, sino porque intento mostrar la discusión de Kant con sus contemporáneos, y especialmente con Garve, que no tiene demasiado lugar en las historias de la filosofía — ni como pensador ni como crítico - pero que fue un interlocutor permanente de Kant y, como tal, arroja nueva luz sobre su obra. Hay quienes, como Filippo Gonnelli, sostienen que Hobbes no es el destinatario de las críticas o, al menos, que Kant no está discutiendo con la filosofía política hobbesiana, sino que el texto en su totalidad en una larga respuesta a Burke, Gentz y Mallet du Pan. Argumentos no le faltan a Gonnelli, pero es imposible resumirlos en este trabajo. Otros autores, por ejemplo Howard Williams, abonan la tesis contraria, interpretan el texto en su totalidad como una larga respuesta a la filosofía política hobbesiana. Gonnelli, Filippo, La filosofía política di Kant, Laterza, 1996, Williams, Howard, Kant's Critique of Hobbes, Cardiff, University of Wales Press, 2003. 
dad feudal estamental. En una carta dirigida a Weisse en 1791, el Garve ya maduro - otrora crítico mordaz de la posición «incoherente», teórico-académica y no «práctica», de Kant ante la Revolución Francesa- se confiesa amedrentado por el poder de las ideas normativas y, aun si con menor patetismo que Burke, Gentz o Rehberg, se aviene a reconocer que:

«... la actual revolución en las ideas es tan rápida y violenta (en Alemania) como la que tiene lugar en los sistemas políticos». ${ }^{25}$

Fácil blanco, éste, para la simpática ironía que el poeta Heine le dedicará más de medio siglo más tarde:

«Tengo la impresión de que un pueblo metódico como nosotros tenía que empezar con la Reforma, podía luego ocuparse de la filosofía, y sólo consumada ésta, podía pasar a la revolución política. Se trataba, por lo demás, de un orden muy razonable. Pues la Revolución puede luego cortar para cualesquiera fines las cabezas que la filosofía haya utilizado ya para la meditación, mientras que la filosofía no habría podido en modo alguno utilizar las cabezas que hubiera cortado la revolución, de haberla precedido» ${ }^{26}$.

Ahora bien, la respuesta de Kant a Garve, en TuP, y la crítica de Garve, en su escrito «Versuche über verschiedene Gegenstände aus der Moral, Literatur und dem gesellschaftlichen Leben» ${ }^{27}$, discurren sobre los verdaderos móviles morales, sobre supuestas «incoherencias» kantianas en lo que hace a la importancia de la felicidad (o de la dignidad de ser felices) en la teoría moral, pero también es una discusión y crítica de Kant al monismo motivacional y el pesimismo antropológico del protoutilitarista Garve, y esta respuesta, a mi modo de ver, es el punto central sobre el que vertebra la discusión.

El concepto kantiano de bien supremo - blanco del ataque de Garve- es demasiado complejo como para exponerlo en este trabajo - no solamente requeriría un análisis de la Dialéctica de la razón práctica sino también de la

25 Batscha, Zwi, «Despotismus...», op. cit., pp. 9 y ss., Garve, C., «Über die Verändungen unserer Zeit in Pädagogik, Theologie und Politik», en Batscha, Zwi, op. cit., pp. 251-278. En este texto Garve se confiesa viejo, enfermo y ante todo, amigo de la tranquilidad, a diferencia de «esas cabezas especulativas que impulsan la revolución, no habiendo tomado parte nunca en los negocios públicos».

${ }^{26}$ Heine, Heinrich: «Religión y filosofía en Alemania», en Obras Completas, traducción, prólogo y notas de Manuel Sacristán, Barcelona, Vergara, pp. 770-771. También Heine se refirió a los filósofos populares de la época como «los que aspiraban a la más burguesa de las claridades» y, en su opinión, Kant deseaba separarse de ellos y, por eso mismo, revistió sus pensamientos con un cortesano y frío lenguaje de cancillería, p. 724. Pero Heine también fue consciente del carácter revolucionario de la crítica kantiana, e incluso dejó dicho que llegará el día en que puedan mostrarse (los kantianos) y llenar el mundo de admiración y espanto..., puesto que la mano del kantiano golpea fuerte y segura, porque su corazón está libre de todo respeto tradicional, p. 771.

27 Garve, C., «Versuche über verschieden Gegenstände aus der Moral, Literatur und dem gesellschaftlichen Leben», en Heinrich, Dieter, op. cit., «Anhang: Christian Garve: Drei Texte über Theorie und Praxis», pp. 133-159. 
concepción kantiana de la historia- y también es demasiado complejo el concepto de bien supremo como para resumirlo en cinco páginas, como lo hizo Garve, desconociendo en todo momento que el deber de promover el bien supremo - la síntesis entre felicidad y virtud - requiere de un proceso histórico de acercamiento entre libertad y naturaleza - porque se trata, claro, de una idea regulativa de la historia - todo lo cual supone una transformación de las disposiciones psicológicas de los hombres y de las instituciones sociales y políticas y, además, una totalización de las intenciones y acciones de los agentes morales trabajando de consuno en vistas a su realización. ${ }^{28}$

Pero el punto medular de la disputa, según creo, y teniendo en cuenta la totalidad de su valiente escrito $T u P$ de 1793, es que Kant objeta al hiperrealista Garve - utilizando para ello argumentos de todo punto realistas - su obstinado empeño por negar la «capacidad de moralidad» al común de los hombres, esto es, la capacidad de obrar desinteresadamente cuando así lo requiere el deber, e independientemente de «ese botín de ventajas en que quieren convertir el cumplimiento del deber». ${ }^{29}$ Es por eso que el realista Kant agrega lo siguiente:

«Que hasta el momento la experiencia histórica no haya querido demostrar el buen éxito de la doctrina de la virtud, es culpa justamente de la falsa suposición de que el móvil emanado de la virtud que deriva de la idea del deber es, en sí mismo, demasiado sutil para el entendimiento común, mientras ese otro móvil más tangible, tomado de ciertas ventajas que cabe esperar - en este mundo e incluso en el mundo futuro- del cumplimiento de la ley (y sin tenerla en cuenta como móvil), actuaría con más fuerza en el ánimo.» ${ }^{30}$

28 Sobre el concepto kantiano de bien supremo y su relación con su filosofía de la historia recomiendo el excelente y clásico libro de Yovel, Yirmiahu, Kant and the Philosophy of History, New Jersey, Princeton University Press, 1980.

${ }_{29}$ Kant, I., TuP, KW, op. cit., p. 288, versión castellana, p. 23.

30 Kant, I., TuP, KW, op . cit., p. 288, versión castellana, op. cit., p. 23. Un argumento similar al que esgrime frente a Garve es el que Kant desarrolla en la tercera parte de TuP, refiriéndose al pesimismo de Mendelssohn acerca de un supuesto progreso del género humano: el género humano «oscila y nunca ha dado un paso adelante sin retroceder después con redoblada velocidad». Ante esta afirmación del «bueno» de Mendelssohn, Kant replicará, por su parte, que por más dudas que la historia pueda extraer en contra de sus esperanzas de lograr una federación de estados con arreglo al Derecho público Internacional, no existen pruebas ciertas para trocar el deber por una regla prudencial que aconseja no dedicarse a lo impracticable. Y, en consonancia con lo dicho en su discusión con Garve, Kant vuelve a repetir que confía tanto en la teoría como en la naturaleza humana, en la cual siempre continúa vivo el respeto por el derecho y el deber; e insiste el filósofo de Königsberg en que no está dispuesto a considerar a esa naturaleza humana hundida en el mal e imposible de ser redimida por medio de la razón práctica. En palabras del propio Kant — que ya hemos citado al comienzo del trabajo pero conviene repetir por su contundencia - todo estaría perdido cuando una práctica calculada en función de un resultado probable, probable con arreglo a la experiencia acumulada hasta la fecha, está autorizada a dominar la teoría. Sobre Kant y Mendelssohn. Kant, I, TuP, KW, VIII, op. cit., pp. 207-213, versión castellana, op. cit., pp. 51-60. La respuesta de Kant a Mendelssohn en este trabajo es incompleta. Para evaluar la diferencia entre ambas posiciones es necesario recu- 
Pedagogos, eclesiásticos, políticos, prácticos y populares - porque a todos ellos va dirigido el escrito kantiano - pretenden que el entendimiento común es incapaz de sutilezas, y recurren a una experiencia histórica que ellos mismos han contribuido a forjar mediante sermones, prácticas institucionales y políticas y, por supuesto, la educación, para mostrar mediante ejemplos históricos aleatoriamente elegidos que el único móvil tangible es un concepto de felicidad ligado al interés de cada cual, el «botín de las ventajas». Kant concluye su breve ensayo contra Garve con una confesión: tiene la esperanza de que el hombre de experiencia - que por eso mismo, por experimentadopresume estar mejor instruido sobre «qué es un hombre y qué se le puede exigir», no vuelva a pedirle al adepto a la teoría —con desdén y orgullo- que «retorne al aula».

\section{Conclusión}

La posición de Kant sobre la necesaria conexión entre teoría y práctica es, en primer lugar, una crítica a Burke, quien, entre otras cosas, recelaba de los inexpertos e imperitos que, levantando el estandarte de «los derechos de los hombres», activaban una mina subterránea, cuyo formidable estallido tenía que destruir todos los ejemplos de la antigüedad, todos los precedentes, todas las constituciones y todas las resoluciones parlamentarias. ${ }^{31}$ También es una respuesta a los burkeanos alemanes Rehberg y Gentz y, por supuesto, al padre de todos los contrarrevolucionarios modernos, a Hobbes, objeto de requisitoria normativa, en éste como en tantos otros escritos de Kant. Pero también al «hombre privado» que, a sus ojos, representa Garve, no menos que al «hombre de mundo» que Kant cree defendido por Mendelssohn. Ambos, Garve y Mendelssohn, fueron coetáneos suyos, y ambos, exponentes destacados de la «filosofía popular». Ambos habían reprochado a Kant, por ejemplo, que se ocupara de lo impracticable en el derecho internacional, porque el género humano oscilaría, pero nunca habría dado un paso adelante sin luego retroceder, según la observación de Mendelssohn ${ }^{32}$;

rrir a sus escritos posteriores, Sobre la Paz Perpetua y la Metafisica de las Costumbres, obras en las cuales Kant desarrolla su concepción de federación de Estados con arreglo al Derecho Público Internacional. Hay un buen artículo sobre este tema de la teleología política en TuP que recomiendo al lector: Flikschuh, K., «Duty, Nature, Right. Kant's Response to Mendelssohn in Theory and Practice III», Journal of Moral Philosophy, vol. IV, 2, 2007, SAGE Publications, pp. 223-241.

31 Burke, Reflections, op. cit., p. 148.

32 No es posible analizar aquí la interesante polémica de Kant con Mendelssohn. Para los fines de este trabajo, importa recordar la pesimista y «realista» concepción mendelssohniana sobre la marcha del género humano, que Kant apodó concepción «abderitista» de la historia: el género humano avanza para luego retroceder. Esta disputa es interesante porque dio lugar a dos concepciones muy distintas sobre el progreso humano, y sobre la posibilidad de una Federa- 
o por otro ejemplo, que no observara los móviles empírico-psicológicos de los hombres, "que son lo único que puede otorgarle constancia y firmeza al sistema moral» ${ }^{33}$, según dejó sentenciado Garve. Ambos, al igual que Feder y Titel, exigían de Kant que abandonara la inútil teoría a favor de la «práctica»; que saliera del aula. Pero lo hacían como tahúres, es decir, reservándose un as en la manga: la filosofía sistemática sólo podría ser popular, cuando un «traductor» adecuado mediara entre las abstrusas especulaciones filosóficas y el público educado. ${ }^{34}$

Kant siempre pensó que la práctica no debía dominar a la teoría, pero también que el libre ejercicio de la razón crítica no era una autoridad dictatorial y debía estar sometido al careo intelectual directo - sin mediación de sedicentes «traductores»- de ciudadanos libres, emancipados de toda tutela, «cada uno de los cuales tiene que poder expresar, sin reservas, sus miramientos y aun su veto». Sin embargo de todo lo cual, y a pesar de ser muchedumbre las afirmaciones de este tenor, Kant era acusado de pedantería filosófica, de hablar sólo para otros filósofos académicos, y hasta de enmarañar deliberadamente el lenguaje para no ser entendido por el público.

Y es evidente que debía ser mucho menos peligroso ser popular y diáfano en la Alemania de finales del XVIII, cuando se trataba de defender la monarquía absoluta con argumentos tomados de la experiencia — como, antes o después, terminaron por hacer Garve y Feder, agarrados de los faldones de la muy empírica noción de orden y tranquilidad-, que cuando se seguía afirmando - como Kant aun después del golpe de Estado de Termidor- que los principios de la razón en la moral y la política eran teóricamente robustos y prácticamente inexcusables en punto a defender la Revolución francesa y los derechos inalienables del pueblo frente a la cabeza del Estado.

ción de Estados que fueran garantía de una paz perpetua. En este punto, la controversia es sobre lo realizable e irrealizable en el ámbito del derecho público internacional, controversia que Kant presentó como otro «malentendido» sobre la supuesta inutilidad de la teoría para la práctica.

33 La prueba que Garve aporta para mostrar la implausibilidad del concepto de bien supremo - una crítica de un tenor similar a la de Pistorius - no es otra que la autopercepción psicológica: «entiendo muy bien esa división de ideas, pero no encuentro en mi corazón semejante división de deseos y aspiraciones». Es ésta la prueba, contundente para Garve, de que la teoría moral kantiana no sirve para la práctica. Sobre la imposibilidad de que el corazón acierte con la división de deseos y aspiraciones, Kant replicará que es bien cierta, pero que vale tanto para el móvil del deber como para cualquier otro influjo que pretenda pasar por único móvil ínsito en el corazón de los hombres, utilizando así el propio argumento de Garve en contra de su aparentemente muy empírico concepto de las motivaciones humanas únicas. Para la discusión con Pistorius: Beiser, F., The fate of Reason. German Philosophy from Kant to Fichte, Cambridge, Harvard University Press, 1984 (Primera Edición 1949), pp. 189 y ss. El capítulo de Beiser: «El ataque de los lockeanos» tiene referencias interesantes y una contextualización de la disputa de Kant con sus contemporáneos que es importantísima para conocer la temprana recepción de la obra kantiana y también para el tema que estamos tratando.

34 C. Garve, Von der Popularität..., op. cit., p. 345. 
Por último, si contextualizamos históricamente la disputa, como pretendía Burke - y recomendaban los «popularizadores»- al confrontar los abstractos derechos de los hombres con los derechos y privilegios reales e históricos de los ciudadanos, se impone la siguiente conclusión:

No es casual que, primero, Hegel, y luego, Marx consideraran que Kant había sido «el teórico de la Revolución francesa». ${ }^{35} \mathrm{Ni}$ lo es que Heine llegara a considerarlo el «terrorista de la filosofía» y a compararlo con Robespierre. Y cuando se entiende esto, se entiende también enseguida que el fondo de la discusión sobre «teoría y práctica» era, en la época, un Politikum de cabo a rabo. Y que sus coetáneos, los «prácticos» (Praktiker), los estadistas y los filósofos mundanos y cismundanos de ningún modo podían desconocer cuáles eran las verdaderas consecuencias prácticas, políticas, de la teoría crítica del filósofo supuestamente confinado por propia voluntad en una simbólica torre de marfil, pero cuyos enemigos querían o, como Burke, encerrar bajo llaves acaso menos simbólicas, o, como Garve, dejarle ver la luz del ágora pública sólo debidamente interpretado por «traductores» eclécticos, guardianes tan celosos del privilegio histórico heredado como enemigos mortales del derecho «abstracto» y de los programas intelectuales normativamente anticipadores del porvenir de un pueblo emancipado de toda tutela.

En las primeras páginas de su escrito tardío Sobre la Paz perpetua, Kant se dirigió con claridad meridiana - con un tono mordaz y francamente político - a quienes lo preferían confinado en el aula y también a aquéllos que lo invitaban a dar un paseo por el mundo; y en esta cita se hace patente que Kant pensaba que ambos, de consuno, creían que su filosofía era un peligro público.

«El autor del presente ensayo pone como condición lo siguiente: que el político práctico sea consecuente, en caso de conflicto con el teórico, y no pretenda ver peligro alguno para el Estado en las opiniones de éste, aventuradas al azar y manifestadas públicamente, ya que suele desdeñar al teórico, cuyas hueras ideas, según el político práctico, no ponen en peligro al Estado que debe arrancar de principios empíricos, y a quien se le puede permitir echar los once bolos de una vez sin que aquél, político de mundo, le haga ningún caso; con esta cláusula salvatoria quiere el autor saberse a cubierto, expresamente y de la mejor forma, de toda interpretación maliciosa...» ${ }^{36}$

35 Hegel, G. W. F., Vorlesungen über die Philosophie der Geschichte. Werke, vol. 12, Suhrkamp, Frankfurt, 1986, p. 525; Marx, Karl, Das philosophische Manifest der historischen Rechtschule, en Karl Marx/Friedrich Engels - Werke. Dietz Verlag, Berlin. Band 1. Berlin/DDR. 1976, p. 80.

36 Kant, I., «Zum Ewigen Frieden, Eine philosophischer Entwurf von Inmanuel Kants», Kants Werke, op. cit., vol. VIII, p. 343. Versión castellana: Sobre la Paz perpetua, traducción de Joaquín Abellán, pp. 3-4. Como aclara el traductor del texto, la frase «echar los once bolos de una vez» significa algo similar a «cribar la nieve» o sea, realizar una tarea francamente inútil. 
Esta deriva interpretativa por parte de sus contemporáneos los prácticos —entre metafísico soñador y peligro público e incluso ambos al mismo tiempo - nunca le resultó indiferente a Kant, como hemos intentado mostrar, al punto que su crítica, en 1793 y también en los escritos posteriores, iba dirigida contra todos ellos: contra quienes le censuran mordazmente la «impopular» prosa y el rigor metodológico de una filosofía sistemática que le confina en la academia, y contra quienes, con indisimulable pugnacidad política, expresan, al revés, el vivo deseo de ver tras los barrotes cualquier intento sistemático de teorización normativa. Todas ellas «interpretaciones maliciosas» frente a las cuales Kant se defiende en los diversos pasajes de su obra que hemos comentado en este trabajo. 